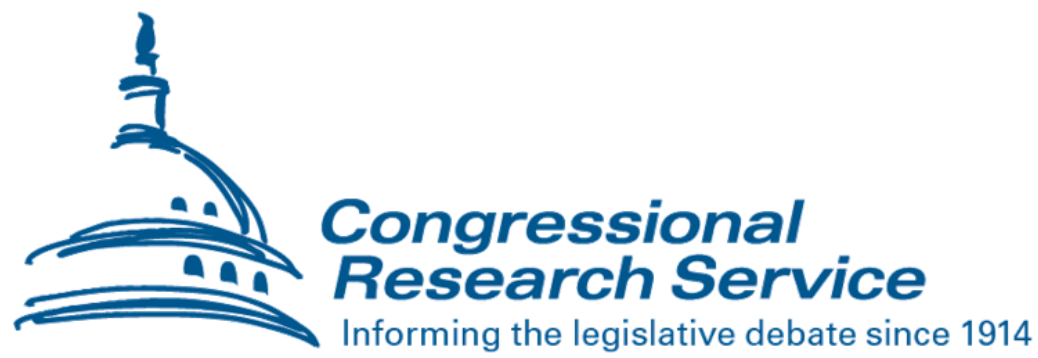

\title{
Health Savings Accounts (HSAs)
}

\author{
Ryan J. Rosso \\ Analyst in Health Care Financing \\ July 31, 2018
}

Congressional Research Service 


\section{Health Savings Accounts (HSAs)}

A health savings account (HSA) is a tax-advantaged account that individuals can use to pay for unreimbursed medical expenses (e.g., deductibles, co-payments, coinsurance, and services not covered by insurance).

Individuals may establish and contribute to an HSA for each month that they are covered under an HSA-qualified high-deductible health plan (HDHP), do not have disqualifying coverage, and cannot be claimed as a dependent on another person's tax return. The account can be established with an insurer, bank, or other Internal Revenue Service (IRS)-approved trustee and is tied to the individual. Account holders retain access to their accounts if they change employers, insurers, or subsequently obtain coverage under a non-HSA qualified plan.

July 31,2018

Ryan J. Rosso

Analyst in Health Care

Financing

rrosso@crs.loc.gov

For a copy of the full report, please call 7-5700 or visit www.crs.gov.

To be considered an HSA-qualified HDHP, a health plan must meet several tests: it must have a deductible above a certain minimum level, it must limit total annual out-of-pocket expenditures for covered benefits to no more than a certain maximum level, and it can provide only preventive care services before the deductible is met. In 2018, HSA-qualified HDHPs must have a minimum deductible of $\$ 1,350$ for self-only coverage and $\$ 2,700$ for family coverage and an annual limit on out-ofpocket expenditures for covered benefits that does not exceed $\$ 6,650$ and $\$ 13,300$, respectively. These amounts are adjusted for inflation (rounded to the nearest \$50) annually.

HSAs have annual contribution limits, which in 2018 are $\$ 3,450$ for individuals with self-only coverage and $\$ 6,900$ for those with family coverage. Eligible individuals may make direct contributions to their HSAs, and employers, family members, and other individuals may make contributions to an individual's HSA on the individual's behalf. In addition to the annual limit, individuals who are at least 55 years of age but not yet enrolled in Medicare may contribute an additional annual catch-up contribution of $\$ 1,000$. The annual contribution limit amounts are adjusted for inflation (rounded to the nearest $\$ 50$ ) annually, but the catch-up contribution amount is fixed. Unused balances may accumulate without limit, be invested, and carry over from year to year.

Individuals do not need to be enrolled in an HSA-eligible HDHP to make withdrawals from the account; however, any withdrawals that are not spent on qualified medical expenses for the account holder, the account holder's spouse, or the account holder's dependents generally are subject to a penalty tax. Qualified medical expenses include the costs of diagnosis, cure, mitigation, treatment, or prevention of disease and the costs for treatments affecting any part of the body; the amounts paid for transportation to receive medical care; and qualified long-term care services. In general, HSAs cannot be used to pay for health insurance premiums or over-the-counter medications.

HSAs have several tax advantages: individual contributions are tax deductible unless made through a pretax salary reduction agreement; employer contributions (including individual contributions made through pretax salary reductions) are excluded from taxable income and from Social Security, Medicare, and unemployment insurance taxes; account earnings are tax exempt; and withdrawals are not taxed if used for qualified medical expenses. However, individuals generally are penalized for withdrawing funds for nonqualified medical expenses and for making contributions above the annual HSA limit.

Although it would be beneficial to study the entire HSA population, which is the population that is eligible to establish and contribute to an HSA (i.e., enrolled in an HSA-eligible HDHP) and the population that has an HSA, few available data sources provide a comprehensive understanding of the entire HSA population. The lack of available data stems in part from the fact that HSAs and HSA-qualified HDHPs are two separate products that can be administered by two separate institutions. As a result, HSA research tends to focus on one of two populations, HSA-qualified HDHP enrollees or HSA holders. Although exact point estimates for the entire HSA/HSA-qualified HDHP population are difficult to determine, current research, when referenced collectively, can highlight various trends. Specifically, multiple different sources have demonstrated continued increases in HSA-qualified HDHP enrollment and HSAs since the mid-2000s. 


\section{Contents}

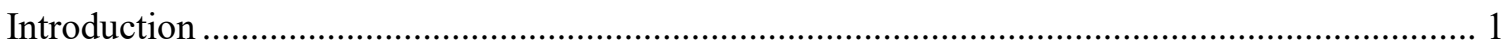

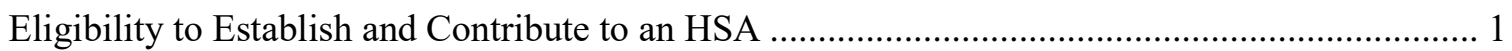

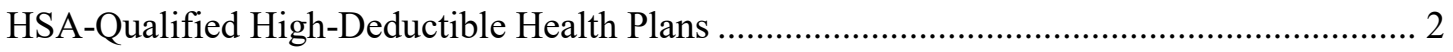

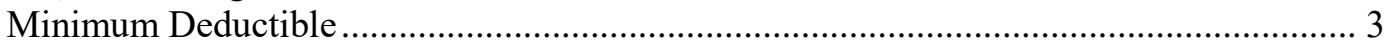

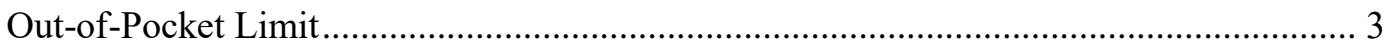

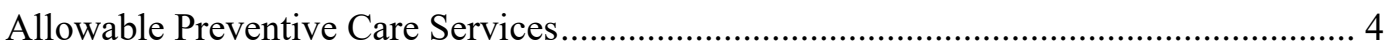

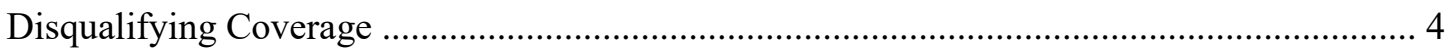

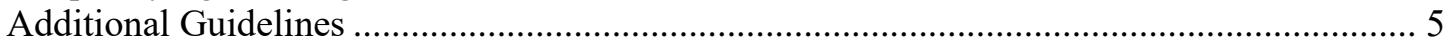

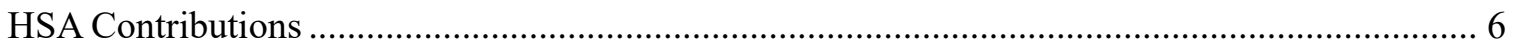

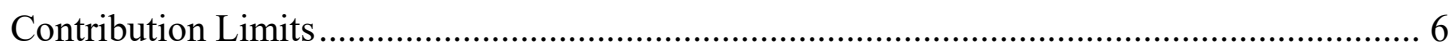

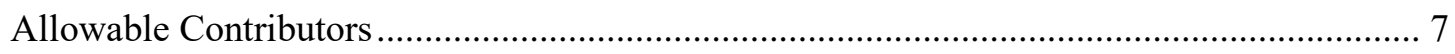

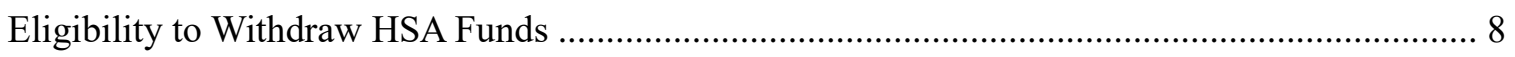

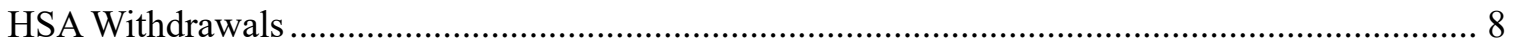

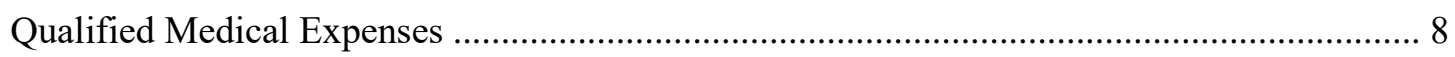

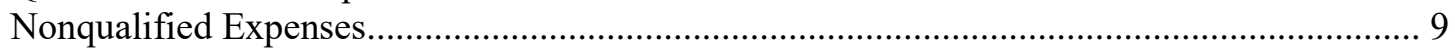

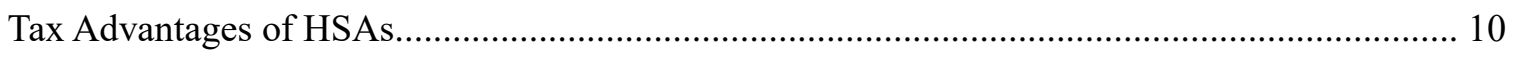

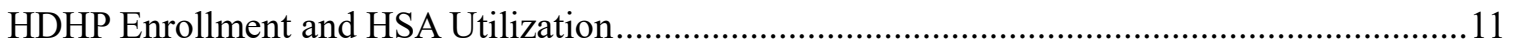

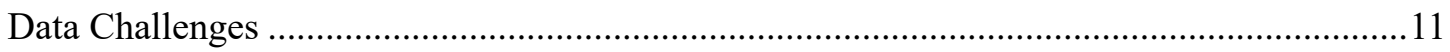

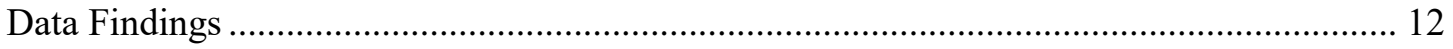

\section{Tables}

Table 1. Health Savings Account (HSA)-Qualified High-Deductible Health Plan (HDHP)

Deductible and Out-of-Pocket Limit Requirements for 2018 .................................................. 2

Table 2. Health Savings Account (HSA) Penalty Taxes ............................................................. 9

Table 3. Tax Advantages of Various Types of Health Savings Account (HSA)

Contributions.

\section{Contacts}

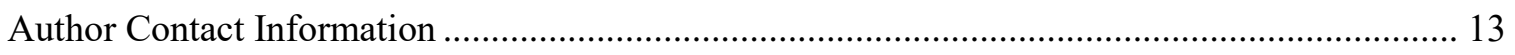




\section{Introduction}

Health savings accounts (HSAs) were first authorized in the Medicare Prescription Drug, Improvement, and Modernization Act of 2003 (P.L. 108-173). HSAs are one type of healthrelated tax-advantaged account that individuals can use to pay for unreimbursed medical expenses (e.g., deductibles, co-payments, coinsurance, and services not covered by insurance). ${ }^{1}$

Generally, individuals are eligible to establish and contribute to an HSA if they have coverage solely under an HSA-qualified high-deductible health plan (HDHP). The HSA is tied to the individual, and account holders retain access to their HSAs if they change employers, insurers, or subsequently obtain coverage under a non-HSA qualified plan. Eligible individuals may make direct contributions to their HSAs, and employers, family members, and other individuals may make contributions to an individual's HSA on the individual's behalf. Unused balances may accumulate without limit, be invested, and carry over from year to year. Individuals do not need to be enrolled in an HSA-eligible HDHP to make withdrawals from the account; however, any withdrawals that are not spent on qualified medical expenses for the account holder, the account holder's spouse, or the account holder's dependents are subject to a penalty tax, with some exceptions.

HSAs have several tax advantages: individual contributions are tax deductible unless made through a pretax salary reduction agreement (see "Allowable Contributors"); employer contributions (and pretax salary reductions) are excluded from taxable income and from Social Security, Medicare, and unemployment insurance taxes; withdrawals are not taxed if used for qualified medical expenses; and account earnings are tax exempt.

This report summarizes the principal rules governing HSAs, covering such matters as eligibility, qualifying health insurance, contributions, withdrawals, and tax advantages. It concludes with a discussion of HSA data limitations and recent research findings on HDHP enrollment and HSA utilization trends.

\section{Eligibility to Establish and Contribute to an HSA}

Individuals are eligible to establish and contribute to an HSA if they have coverage under an HSA-qualified HDHP, do not have disqualifying coverage (disqualifying coverage is discussed in the section, "Disqualifying Coverage"), and cannot be claimed as a dependent on another person's tax return. ${ }^{2}$

\footnotetext{
${ }^{1}$ Other health-related tax-advantaged accounts include flexible spending accounts (FSAs), Archer medical savings accounts (Archer MSAs), health reimbursement accounts (HRAs), and qualified small employer health reimbursement arrangements (QSEHRAs). FSAs are employer-established accounts that can be offered to employees. They began to spread in the 1980s, once the Internal Revenue Service (IRS) established clear guidelines. Archer MSAs, a precursor of health savings accounts (HSAs), became available for a limited number of people starting in 1997. HRAs-which, like FSAs, are employer-established accounts that can be offered to employees - were first affirmed by the IRS as a taxadvantaged way to pay for unreimbursed medical expenses in guidance issued in 2002. Established in 2016, QSEHRAs are employer-established accounts that are available exclusively to small employers and can be offered to employees to pay for unreimbursed medical expenses.

2 Dependent, as defined at 26 U.S.C. $\$ 7706$, is determined without regard to 26 U.S.C. $\$ 7706(b)(1)$, (b)(2), and (d)(1)(B). Prior to the Tax Cuts and Jobs Act (P.L. 115-97), this definition was found at 26 U.S.C. §152. Although P.L. 115-97 removed the dependent exemption, it retained and relocated the definition of dependent as referenced for the execution of HSAs. Tax dependency is determined on a yearly basis and might not be known until the end of the year. IRS, Publication 969: Health Savings Accounts and Other Tax-Favored Health Plans, March 1, 2018, p. 3, at
} 
Whether someone qualifies for an HSA is determined as of the first of each month; thus, a person might be eligible to contribute to an HSA in some months but not in others. For example, if someone first enrolled in an HDHP on September 15, his or her HSA eligibility period would begin on October 1 of that year. Individuals may keep their HSAs and withdraw funds if they become ineligible but cannot make contributions until they become eligible once again.

All eligible individuals have the flexibility to establish an HSA with an institution other than their insurer, if at all. Accounts may be established with banks, insurance companies, or other entities approved by the Internal Revenue Service (IRS) to hold individual retirement accounts (IRAs) or Archer medical savings accounts (Archer MSAs). Additional nonbank entities may become an HSA trustee or custodian but first must request approval from the IRS. ${ }^{3}$

\section{HSA-Qualified High-Deductible Health Plans}

To be HSA qualified, a health plan must meet several tests: it must have a deductible above a certain minimum level, it must limit out-of-pocket expenditures for covered benefits to no more than a certain maximum level, and it can cover only preventive care services before the deductible is met. ${ }^{4}$ (See Table 1 for the minimum deductibles and out-of-pocket limits for 2018.) In addition, the plan's coverage cannot be limited to a narrow set of services, such as coverage for a particular disease (e.g., cancer-only coverage) or vision-only coverage. ${ }^{5}$ This rule is designed to prevent individuals from establishing and making HSA contributions when the only insurance they have is coverage for a narrow class of benefits.

Table I. Health Savings Account (HSA)-Qualified High-Deductible Health Plan (HDHP) Deductible and Out-of-Pocket Limit Requirements for 2018

\begin{tabular}{lcc}
\hline \multicolumn{1}{c}{ Requirement } & Self-Only Plan & Family Plan \\
\hline Minimum Deductible & $\$ 1,350$ & $\$ 2,700$ \\
Out-of-Pocket Limit & $\$ 6,650$ & $\$ 13,300$ \\
\hline
\end{tabular}

Source: Internal Revenue Service (IRS), Internal Revenue Bulletin: 2018-10, Revenue Procedure 20I8-18, March 5, 2018, at https://www.irs.gov/irb/20I8-I0_IRB\#RP-20I8-I8.

Notes: Not all HDHPs are considered HSA-qualified HDHPs. As an example, plans may meet the deductible and out-of-pocket limits but may cover more than preventive care services before the deductible is met. Minimum deductible and out-of-pocket limits apply only to in-network payments for usual, customary, and reasonable (UCR) charges. UCR is defined as "the amount paid for a medical service in a geographic area based on what providers in the area usually charge for the same or similar medical service." Centers for Medicare \& Medicaid, Glossary, at https://www.healthcare.gov/glossary/ucr-usual-customary-and-reasonable/.

https://www.irs.gov/pub/irs-pdf/p969.pdf. Hereinafter IRS, Publication 969.

${ }^{3}$ IRS, Internal Revenue Bulletin: 2004-2, Notice 2004-2, January 12, 2004, at https://www.irs.gov/irb/200402_IRB\#NOT-2004-2. Hereinafter IRS, Internal Revenue Bulletin: 2004-2.

${ }^{4}$ IRS, Publication 969, p. 3. Individuals should be able to find out from their insurer whether their high-deductible health plan (HDHP) is HSA qualified. They cannot apply to the IRS or another government agency for a determination.

526 U.S.C. \$223(c)(2)(B). 


\section{Minimum Deductible}

To be HSA qualified, a health plan's annual deductible in 2018 must be at least $\$ 1,350$ for selfonly coverage; for family coverage, it must be at least $\$ 2,700 .^{6}$ These amounts are adjusted for inflation (rounded to the nearest \$50) annually. ${ }^{7}$

In addition, a health plan is required to take into account only usual, customary, and reasonable charges for covered benefits that are provided in network when determining whether deductibles are met. ${ }^{8}$ Premiums cannot be included in meeting the deductible.

If a health plan has deductible (and co-payment) requirements for prescription drugs that are different than requirements for other benefits, in order for the plan to be HSA qualified, the prescription drug deductible still must meet the same minimum requirements. ${ }^{9}$

If an enrollee uses a prescription or other discount card that reduces the amount that the enrollee pays out of pocket for certain items or services, then an HSA-qualified plan nonetheless must count the full amount (what the enrollee paid out of pocket plus the amount of the discount) toward meeting the plan's deductible. ${ }^{10}$

\section{Out-of-Pocket Limit}

To be HSA qualified, a health plan's annual limit on out-of-pocket expenditures for covered benefits must not exceed $\$ 6,650$ in 2018 for self-only coverage. For family policies, the limit must not exceed $\$ 13,300 .{ }^{11}$ These amounts are adjusted for inflation (rounded to the nearest $\$ 50$ ) annually.

All enrollee cost sharing — deductibles, co-payments, and coinsurance—for in-network coverage provided under the HSA-qualified HDHP is taken into account in determining whether the out-ofpocket limits are exceeded. However, these limits should not be interpreted as ceilings on all outof-pocket expenditures for health care. Enrollee payments to providers for benefits provided out of network or not covered by the HSA-qualified HDHP do not count toward the out-of-pocket limit, nor do premiums for the HSA-qualified HDHP and any other insurance. Even for covered

\footnotetext{
${ }^{6}$ IRS, Internal Revenue Bulletin: 2018-10, Revenue Procedure 2018-18, March 5, 2018, at https://www.irs.gov/irb/ 2018-10_IRB\#RP-2018-18. Hereinafter IRS, Internal Revenue Bulletin: 2018-10.

${ }^{7}$ This and other HSA inflation adjustments are based upon the Consumer Price Index for All Urban Consumers published by the U.S. Department of Labor. 26 U.S.C. $\$ 223(\mathrm{~g})(1)(B)$ provides that the measurement period for HSA inflation adjustments is the 12-month period ending on March 31 of the prior year.

${ }^{8}$ Usual, customary, and reasonable (UCR) is defined by the Centers for Medicare \& Medicaid as "the amount paid for a medical service in a geographic area based on what providers in the area usually charge for the same or similar medical service." Centers for Medicare \& Medicaid, Glossary, at https://www.healthcare.gov/glossary/ucr-usualcustomary-and-reasonable/. If an enrollee pays a provider an amount greater than the UCR, then any amount above the UCR does not count toward to the deductible.

${ }^{9}$ Certain drugs may be considered preventive care if they are "taken by a person who has developed risk factors for a disease that has not yet manifested itself or not yet become clinically apparent, or to prevent the reoccurrence of a disease from which a person has recovered." In these instances, plans can treat preventive care prescription drugs like any other preventive service and provide these drugs without a deductible or with a deductible less than the required minimum annual deductible. IRS, Internal Revenue Bulletin: 2004-33, Notice 2004-50, August 16, 2004, at https://www.irs.gov/irb/2004-33_IRB\#NOT-2004-50. Hereinafter IRS, Internal Revenue Bulletin: 2004-33.

${ }^{10}$ IRS, Internal Revenue Bulletin: 2004-33.

${ }^{11}$ IRS, Internal Revenue Bulletin: 2018-10.
} 
benefits provided in network, the limits apply only to payments for usual, customary, and reasonable charges, as defined in the previous section. ${ }^{12}$

\section{Allowable Preventive Care Services}

Health plans that otherwise meet the requirements to be HSA qualified are not disqualified if they do not have a deductible for preventive care services, as defined in the Internal Revenue Code and IRS-issued guidance, ${ }^{13}$ or if they have a deductible less than the aforementioned minimum annual deductible for those services. IRS guidance provides that preventive care includes, but is not limited to, periodic health evaluations (including tests and diagnostic procedures ordered in connection with routine examinations), routine prenatal and well-child care, immunizations, tobacco cessation programs, obesity weight-loss programs, and various screening services. ${ }^{14}$ Drugs and medications can be considered preventive care when taken by a person who has developed risk factors for a disease or is preventing its recurrence. ${ }^{15}$ In general, preventive care does not include services or benefits intended to treat existing illnesses, injuries, or conditions, although an exception is allowed when the treatment is incidental to a preventive care service and it would be unreasonable or impracticable to perform another service for treatment. ${ }^{16}$

Additionally, HSA-qualified HDHPs are required to comply with the federal requirement in Section 2713 of the Public Health Service Act to provide specified preventive care services without imposing cost sharing. ${ }^{17}$ For this requirement, preventive care includes evidenced-based services that have in effect a rating of "A" or "B" in the current recommendations of the United States Preventive Services Task Force, routine immunizations, and other evidence-based preventive care and screenings for women and children. ${ }^{18}$ Because this requirement provides that health plans, including HSA-qualified HDHPs, cannot impose any cost sharing for the specified preventive services, all such services must be covered by HSA-qualified HDHPs before the plan's deductible is met.

\section{Disqualifying Coverage}

There are a number of ways in which an individual could be disqualified from establishing and contributing to an HSA, even if the individual has coverage under an HSA-qualified HDHP.

Individuals generally must not have any other health coverage that is not an HSA-qualified HDHP or that provides coverage for any benefit that is covered under their HSA-qualified

\footnotetext{
12 IRS, Internal Revenue Bulletin: 2004-33.

1326 U.S.C. §223(c)(2)(C). IRS, Internal Revenue Bulletin: 2004-15, Notice 2004-23, April 12, 2004, at https://www.irs.gov/irb/2004-15_IRB\#NOT-2004-23. Hereinafter IRS, Internal Revenue Bulletin: 2004-15.

14 IRS, Publication 969, p. 3, and IRS, Internal Revenue Bulletin: 2004-15.

${ }^{15}$ IRS, Internal Revenue Bulletin: 2004-33.

${ }^{16}$ IRS, Internal Revenue Bulletin: 2004-33.

${ }^{17}$ IRS, Internal Revenue Bulletin: 2013-40, Notice 2013-57, September 30, 2013, at https://www.irs.gov/irb/201340_IRB\#NOT-2013-57 and 42 U.S.C. $\$ 300 g g-13$.

1842 U.S.C. $\$ 300 \mathrm{gg}-13$. For more information about preventive care services, see Department of Health and Human Services, "Preventive Care," February 1, 2017, at https://www.hhs.gov/healthcare/about-the-aca/preventive-care/ index.html. The United States Preventive Services Task Force is an independent, volunteer panel of experts in prevention, evidence-based medicine, and primary care. The task force makes preventive care recommendations and assigns each recommendation a letter grade based on the strength of the evidence supporting the recommendation. For more information about the task force, see U.S. Preventive Services Task Force, "About the USPSTF,"

https://www.uspreventiveservicestaskforce.org/.
} 
HDHP. ${ }^{19}$ For example, individuals with an HSA-qualified HDHP are not eligible to establish or contribute to an HSA if they also are covered under a spouse's policy that is not an HSA-qualified HDHP for the same benefits.

Individuals are not allowed to establish or contribute to an HSA if they are enrolled in Medicare, which generally first occurs at the age of $65 .{ }^{20}$

\section{Additional Guidelines}

Some types of health coverage are not considered disqualifying for purposes of being eligible to establish and contribute to an HSA. ${ }^{21}$ Coverage for any benefit provided under permitted insurance, ${ }^{22}$ and coverage (through insurance or otherwise) for accidents, disability, vision care, dental care, or long-term care, is not considered disqualifying health coverage.

HSA-qualified HDHP enrollees who do not have disqualifying coverage still are considered HSA eligible even if they have access to and coverage under an employee assistance program, disease management program, or wellness program, provided the program does not provide "significant benefits in the nature of medical care or treatment." 23 HSA-qualified HDHP enrollees who receive treatment under the Veterans Health Administration, within the Department of Veterans Affairs, for service-connected disabilities also are still HSA-eligible. ${ }^{24}$

HSA-eligible individuals generally may not have employer-established flexible spending accounts and health reimbursement accounts, which are two other types of health-related taxadvantaged accounts, unless these accounts (1) are for limited purposes (for example, dental services or preventive care), (2) provide reimbursement for services covered by the HSAqualified HDHP only after the qualifying deductible is met, or (3) are used in retirement. ${ }^{25}$

\footnotetext{
1926 U.S.C. $\$ 223(\mathrm{c})(1)(\mathrm{A})(\mathrm{ii})$.

${ }^{20}$ Although the law states that eligible individuals are no longer able to establish and contribute to HSAs after becoming "entitled to benefits" under Medicare, the IRS interprets the phrase "entitled to benefits" as meaning "eligibility and enrollment" in either Medicare Part A or Medicare Part B. 26 U.S.C. §223(b)(7) and IRS, Internal Revenue Bulletin: 2004-33.

${ }^{21}$ Inversely, although individuals are allowed to have these additional types of coverage (in conjuncture with an HSAqualified HDHP) and remain HSA eligible, any combination of plans in which all of the coverage is through permitted insurance and/or coverage for accidents, disability, vision care, dental care or long-term care would not be considered an HSA-qualified HDHP. Therefore, an individual would not be eligible for an HSA with only these types of insurance. IRS, Publication 969, p. 4.

${ }^{22}$ Permitted insurance is defined at 26 U.S.C. \$223(c)(3) as insurance under which substantially all coverage relates to liabilities incurred under workers' compensation laws, tort liabilities, or liabilities related to ownership or use of property (such as automobile insurance); insurance for a specified disease or illness; or insurance that pays a fixed amount per day or other period of hospitalization.

${ }^{23}$ Screening and other preventive care services are not considered "significant benefits in the nature of medical care or treatment." IRS, Internal Revenue Bulletin: 2004-33.

${ }^{24} 26$ U.S.C. $\$ 223(c)(1)(C)$. Service-connected disability within the meaning of 38 U.S.C. $\$ 101(16)$.

${ }^{25}$ IRS, Internal Revenue Bulletin: 2004-22, Revised Rule 2004-45, June 1, 2004, at https://www.irs.gov/irb/200422_IRB\#RR-2004-45.
} 


\section{HSA Contributions}

\section{Contribution Limits}

HSAs have annual contribution limits. In 2018 , the annual contribution limit is $\$ 3,450$ for selfonly coverage and $\$ 6,900$ for family coverage. ${ }^{26}$ The applicable annual limits apply to total contributions to the HSA from all sources (e.g., from individuals and employers). These amounts are adjusted for inflation (rounded to the nearest \$50) annually. In addition to the annual limit, account holders who are at least 55 years of age may contribute an additional catch-up contribution of $\$ 1,000$ each year, which is not annually indexed for inflation. Where applicable, these annual limits must be reduced by the amount of any contributions individuals make to their Archer MSAs during the same year or for any direct contributions from traditional or Roth IRAs, the latter of which is discussed further later in this section.

Contributions to HSAs may be made at any time during a calendar year and until the federal income tax return filing date (without extensions), normally April 15 of the following year. ${ }^{27}$ Thus, contributions could occur over a 151/2-month time span (e.g., from January 1, 2018, through April 15, 2019), provided they do not exceed the allowable annual limit.

The annual limits are calculated on a monthly basis: for each month during the year when individuals are eligible, they may contribute (or others may contribute on their behalf) up to onetwelfth of the applicable annual limit. For example, an individual who is eligible from January through July could contribute seven-twelfths of the annual limit for that year.

As an exception to this rule, individuals who are eligible during the last month of the year are treated as if they had been eligible for that entire year and thus are allowed to contribute up to the annual limit so long as the contribution is before the tax filing date of the following year (see below) ${ }^{28}$ Individuals who make contributions under this rule must maintain their HSA eligibility for the entire following year, the testing period, except in cases of disability or death. ${ }^{29}$ Otherwise, the additional contributions are included in gross income when determining federal income taxes for the year in which an individual fails to be a HSA eligible and, as shown in Table 2 , are subject to a $10 \%$ penalty tax.

Any excess contributions to an HSA are not tax deductible and, if made by an employer, are treated as gross income for the tax year in which the contributions were earned. Excess contributions generally are subject to a $6 \%$ penalty tax, unless the excess amounts are withdrawn prior to the tax filing date of the year the excess contributions were made. ${ }^{30}$ If not withdrawn, this penalty tax would apply to each tax year the excess contributions remain in the account.

\footnotetext{
${ }^{26}$ IRS, Internal Revenue Bulletin: 2018-10, and IRS, Revenue Procedure 2018-27, April 26, 2018, at https://www.irs.gov/pub/irs-drop/rp-18-27.pdf.

${ }^{27}$ IRS, Internal Revenue Bulletin: 2004-2.

2826 U.S.C. $\$ 223(\mathrm{~b})(8)$.

2926 U.S.C. $\$ 223(\mathrm{~b})(8)(\mathrm{iii})$.

3026 U.S.C. \$4973(a) and (g). As an example, if individual who is HSA eligible from January through July contributes more than seven-twelfths of the annual limit for that year, then that individual has until that year's tax filing date to withdraw the excess contributions. If the funds are not withdrawn, the excess contributions would be subject to a $6 \%$ penalty tax. IRS, Publication 969, pp. 7-8.
} 


\section{Allowable Contributors}

Eligible individuals may make direct contributions to their HSAs, and employers, family members, and other individuals may make contributions to an individual's HSA on the individual's behalf. ${ }^{31}$ Contributions by one individual or entity do not preclude contributions by others, provided the total amount of contributions does not exceed annual contribution limits. ${ }^{32}$

Employed individuals may make HSA contributions through pretax salary reduction agreements - that is, benefit arrangements established by employers under which employees accept lower take-home pay in exchange for the difference being deposited in their benefit account. ${ }^{33}$ Because these types of individual contributions are excluded from gross income, they are not tax deductible. The IRS has determined that salary reduction agreements must allow employees to stop, increase, or decrease their HSA contributions throughout the year as long as the changes are effective prospectively; however, employers may place restrictions on HSA contribution elections under this type of arrangement if the restrictions apply to all employees. ${ }^{34}$ The IRS also has determined that these agreements allow employers to make an employee's annual expected HSA contribution available to the employee so that the employee may cover medical expenses that exceed his or her current HSA balances, provided the employee repays the accelerated contributions before the end of the year. ${ }^{35}$

HSA contributors cannot restrict how HSA funds are used. For example, employers may not limit HSAs to certain medical expenses (or medical expenses only), even for funds they contribute. ${ }^{36}$ Therefore, account owners may make withdrawals for any purpose, though nonqualified withdrawals are subject to taxation, as discussed in the section "Nonqualified Expenses."

Eligible individuals may use other tax-advantaged accounts to increase the amount of resources available in their HSAs. Specifically, individuals may make one rollover contribution to an HSA from an Archer MSA or another HSA during a one-year period. ${ }^{37}$ Individuals also may make a once-in-a-lifetime distribution from their traditional or Roth IRA and deposit it into an HSA, which is factored into the annual contribution limits described in the "Contribution Limits"

\footnotetext{
${ }^{31}$ An employer's contributions to employees' HSAs are subject to 26 U.S.C. 4980G, which requires the employer to provide comparable HSA contributions to all comparable participating employees, unless the employer makes the HSA contributions through a pretax salary reductions (often referred to as a cafeteria plan). If an employer contributes to employees' HSAs under a cafeteria plan, then the contributions are subject to the cafeteria plan nondiscrimination rules. For more details, see IRS, Internal Revenue Bulletin: 2004-33, and IRS, Publication 969, pp. 7-8; and 26 U.S.C. $\S 223(\mathrm{~b})(4)$.

3226 U.S.C. $\$ 223(\mathrm{~b})(4)$. There are additional rules regarding married couples and HSAs. For more information on HSA rules for married people, see IRS, Publication 969, pp. 7-8.

${ }^{33}$ In general, pretax salary reduction agreements are established as cafeteria plans under 26 U.S.C. $\$ 125$. Under a cafeteria plan, an employer can give an employee the choice between taxable (e.g., cash) and nontaxable benefits without being taxed on the value of the benefits if the employee selects the nontaxable benefits. HSA contributions made in this manner are treated as employer contributions and are excluded from the employee's income for federal tax purposes (and are not deductible by the employee).

${ }^{34}$ IRS, Internal Revenue Bulletin: 2004-33.

35 IRS, Internal Revenue Bulletin: 2004-33.

36 IRS, Internal Revenue Bulletin: 2004-33.

${ }^{37}$ There is no limit on the number of HSA rollovers if they are sent directly from one trustee to another. Additionally, individuals do not need to be HSA-eligible to roll over funds from an existing HSA to a new HSA. IRS, Publication 969, pp. 7-8.
} 
section. ${ }^{38}$ These types of HSA contributions are subject to different tax rules than regular HSA contributions, as discussed in the "Tax Advantages of HSAs" section.

\section{Eligibility to Withdraw HSA Funds}

An account holder may withdraw HSA funds at any time. Generally, withdrawals must be used for qualified medical expenses for the account holder, the account holder's spouse, or the account holder's dependents. ${ }^{39}$ Any withdrawals for nonqualified expenses must be included in the account holder's gross income when determining federal income taxes and are subject to an additional $20 \%$ penalty. ${ }^{40}$ Neither the account holder nor the account holder's spouse or dependents need to be covered under the same or separate HSA-qualified HDHPs for the account holder to withdraw funds. Likewise, having disqualifying coverage would not prohibit an account holder from withdrawing HSA funds. For example, an account holder who enrolls in Medicare Parts A and B becomes ineligible to establish or contribute to an HSA, but the account holder may continue to withdraw funds from a previously established HSA. ${ }^{41}$

\section{HSA Withdrawals}

\section{Qualified Medical Expenses}

As noted above, HSA withdrawals are exempt from federal income taxes if used to cover qualified medical expenses for the account holder, the account holder's spouse, or the account holder's dependents. HSA withdrawals remain exempt from federal income taxes even if these individuals are not covered under an HSA-qualified HDHP or have disqualifying coverage.

For HSA purposes, qualified medical expenses are considered most medical care described in 26 U.S.C. $\S 213(\mathrm{~d})$ and further explained in IRS publication 502, Medical and Dental Expenses. ${ }^{42}$ More specifically, qualified medical expenses are defined as including the following: the costs of diagnosis, cure, mitigation, treatment, or prevention of disease and the costs for treatments affecting any part of the body; the amounts paid for transportation to receive medical care; and qualified long-term care services. ${ }^{43}$

\footnotetext{
3826 U.S.C. $\$ 408(d)(9)$.

${ }^{39}$ In this context, the term dependent includes all dependents that the account holder claims on his/her tax return and any person the account holder could have claimed as a dependent on his/her tax return except that (a) the person filed a joint return, (b) the person had a gross income of $\$ 4,050$ or more, or (c) the account holder could have been claimed as a dependent on someone else's return. IRS, Publication 969, p. 8.

${ }^{40}$ Nonmedical HSA distributions for those aged 65 and older are treated as ordinary income and are not subject to a penalty.

${ }^{41}$ Because account holders aged 65 and older can withdraw funds from an HSA and use them for any purpose penalty free, some may consider an HSA to be a tax-sheltered retirement account that is more advantageous than other retirement savings plans. Paul Fronstin, Investment Options and HSAs: Findings from the EBRI HSA Database, Employee Benefit Research Institute, August 2015, p. 2, at https://www.ebri.org/pdf/notespdf/ EBRI_Notes_08_Aug15_HSAs-QLACs.pdf.

${ }^{42}$ Qualified medical expenses that were paid for with an HSA withdrawal cannot be used for a medical and dental expenses deduction. IRS, Publication 502 (2017), Medical and Dental Expenses, December 8, 2017, at https://www.irs.gov/publications/p502. Hereinafter IRS, Publication 502.

${ }^{43}$ A nonexclusive list of qualified medical expenses can be found in IRS, Publication 502. Also see 26 U.S.C. §213(d).
} 
However, of the medical expenses mentioned in 26 U.S.C. §213(d), health insurance premiums and over-the-counter medicines (i.e., medicines available without a prescription) are not considered qualified medical expenses for HSA purposes. ${ }^{44}$

In general, HSAs cannot be used to pay health insurance premiums. However, premiums for four types of insurance are considered to be qualified HSA expenses: (1) long-term care insurance, (2) health insurance premiums during periods of continuation coverage required by federal law (e.g., Consolidated Omnibus Budget Reconciliation Act coverage, or COBRA), (3) health insurance premiums during periods in which the individual is receiving unemployment compensation, and (4) for individuals aged 65 years and older, any health insurance premiums (including Medicare Part B premiums) other than a Medicare supplemental policy. ${ }^{45}$

There is no time limit on when HSA withdrawals need to be made to pay for (or reimburse payments for) qualified medical expenses, provided adequate records are kept. ${ }^{46}$ However, HSAs may not be used to pay expenses incurred before the HSA was established. For example, an account holder may pay 2017 qualified medical expenses today using funds from an HSA established in 2016 but may not use the account to pay for qualified medical expenses incurred in 2015 , since this was before the account was established.

\section{Nonqualified Expenses}

Withdrawals not used to pay for qualified medical expenses must be included in the account holder's gross income when determining federal income taxes and are subject to a $20 \%$ penalty, as shown in Table 2. The penalty is waived in cases of disability or death and for individuals aged 65 and older; however, withdrawals for nonqualified expenses still may be treated as gross income. ${ }^{47}$ There is no requirement, as there is for qualified retirement plans, that individuals begin to spend down account balances at a certain age.

Table 2. Health Savings Account (HSA) Penalty Taxes

\begin{tabular}{lccc}
\hline \multicolumn{1}{c}{ Penalty Tax } & Tax Percentage & \multicolumn{1}{c}{ Tax Base } & Authorizing Law \\
\hline $\begin{array}{l}\text { Withdrawal of Funds for } \\
\begin{array}{l}\text { Nonqualified Medical } \\
\text { Expenses }\end{array}\end{array}$ & $20 \%$ & Amount of Withdrawal & 26 U.S.C. §223(f)(4) \\
$\begin{array}{l}\text { Failure to Maintain HSA } \\
\begin{array}{l}\text { Eligibility During Testing } \\
\text { Periodb }\end{array}\end{array}$ & $10 \%$ & $\begin{array}{l}\text { Contributions into HSA } \\
\text { for Months Not Covered } \\
\text { by HSA-Qualified HDHP }\end{array}$ & 26 U.S.C. §223(b)(8) \\
$\begin{array}{l}\text { Excess Contributions } \\
\text { Above HSA Annual Limit }\end{array}$ & $6 \%$ & $\begin{array}{l}\text { Additional Contribution } \\
\text { Amount }\end{array}$ & 26 U.S.C. \$4973(a) and (g) \\
\hline
\end{tabular}

Source: Congressional Research Service analysis of tax code.

a. The penalty is waived in cases of disability or death and for individuals aged 65 and older.

b. Individuals who are eligible during the last month of the year are treated as if they had been eligible for the entire year and thus are allowed to contribute up to the annual limit. Individuals who make additional

${ }^{44}$ IRS, Publication 969, p. 8, and IRS, Internal Revenue Bulletin: 2004-33.

45 IRS, Publication 969, p. 8.https://www.irs.gov/pub/irs-pdf/p969.pdf.

46 IRS, Internal Revenue Bulletin: 2004-33.

${ }^{47} 26$ U.S.C. §223(f)(4). If the account holder dies and the account holder's spouse inherits the HSA, the spouse becomes the account holder. If someone other than the account holder inherits the account, the account ceases to be an HSA and must be included as gross income by the inheritor. 26 U.S.C. §223(f)(8)(A). 
contributions under this rule must maintain their HSA eligibility for the following year, the testing period, except in cases of disability or death.

\section{Tax Advantages of HSAs}

HSAs often are referred to as having a triple tax advantage: (1) contributions reduce taxable income, (2) earnings on the account grow tax free, and (3) withdrawals for qualified medical expenses are not subject to taxation. ${ }^{48}$

Qualified individuals who contribute to their HSAs may claim a deduction on their federal income tax return and thus reduce their tax burden, as shown in Table $3 .{ }^{49}$ The deduction is above the line; that is, it is made in determining adjusted gross income and may be taken by taxpayers regardless of whether they claim the standard deduction or the itemized deduction.

Table 3.Tax Advantages of Various Types of Health Savings Account (HSA) Contributions

\begin{tabular}{lccc}
\hline $\begin{array}{c}\text { HSA Contribution } \\
\text { Type }\end{array}$ & $\begin{array}{c}\text { Can Be Used to Claim } \\
\text { Federal HSA Tax } \\
\text { Deduction }\end{array}$ & $\begin{array}{c}\text { Counts as Federal } \\
\text { Taxable Income }\end{array}$ & $\begin{array}{c}\text { Counts Toward } \\
\text { Annual HSA } \\
\text { Contribution Limit }\end{array}$ \\
\hline $\begin{array}{l}\text { Individual Contributiona } \\
\text { Employer Contributionb }\end{array}$ & Yes & No & No \\
$\begin{array}{l}\text { Traditional or Roth IRA } \\
\text { Distribution to HSAc } \\
\begin{array}{l}\text { Archer MSA and Other } \\
\text { HSA Rollover }\end{array}\end{array}$ & No & No & Yes \\
Investment Earnings & No & No & Yes \\
\hline
\end{tabular}

Source: IRS, Publication 969: Health Savings Accounts and Other Tax-Favored Health Plans, March I, 20I8, at https://www.irs.gov/pub/irs-pdf/p969.pdf.

Notes: Excess HSA contributions count toward gross income, cannot be used to claim the HSA tax deduction, and are subject to a $6 \%$ penalty tax.

a. Includes account holder contributions and other contributions made by individuals on behalf of the account holder (not including employer contributions).

b. Includes employee contributions made through a pretax salary reduction agreement.

c. A once-in-a-lifetime traditional or Roth individual retirement account (IRA) distribution to an HSA would not be subject to early IRA withdrawal penalties.

Individuals may claim the tax deduction for all amounts contributed to their HSAs that were made either by the individual or on behalf of the individual (not including employer amounts or contributions made through a pretax salary reduction agreement) over the course of the year through the subsequent tax filing deadline. For individuals claiming the deduction, the total tax effect of the eligible HSA contributions depends on an individual's marginal tax rate and the amount of nonemployer contributions to the individual's HSA.

\footnotetext{
${ }^{48}$ Employee Benefit Research Institute, The Triple Tax Advantage of an HSA, July 31, 2014, at https://www.ebri.org/ pdf/ff.292.hsa-tax.31july14.pdf.

${ }^{49}$ Individuals who may be claimed as a dependent are not eligible to establish an HSA; therefore, they are not eligible for this deduction.
} 
No deduction may be claimed for a once-in-a-lifetime contribution from an IRA (though the IRA distribution is not penalized, as it otherwise might be) or for Archer MSA or other HSA rollovers. ${ }^{50}$ These amounts do not count as gross income in determining income tax liability. ${ }^{51}$

An employer's contributions to an HSA cannot be deducted by employees as HSA contributions or as medical expense deductions; however, they are excluded from employees' gross income in determining their income tax liability. ${ }^{52}$ In addition, the employer's contributions are excluded from Social Security and Medicare taxes for both employers and employees and are excluded from federal unemployment insurance taxes..$^{53}$ If an employee contributes to his or her HSA through a pretax salary reduction agreement, the contributions are considered to be made by the employer and are excluded from the employee's gross income in determining his or her income tax liability and are exempt from the three employment taxes (Social Security, Medicare, and unemployment insurance taxes). An employee cannot deduct amounts contributed to an HSA through a pretax salary reduction agreement.

HSA balances can be invested similar to IRAs (e.g., annuities, stocks, mutual funds, bonds, etc.), and any associated earnings can accumulate tax free. ${ }^{54}$

State income taxes generally follow federal rules with respect to deductions and exclusions. However, some states may choose to provide different treatment. For example, California does not recognize HSAs as tax-advantaged accounts. ${ }^{55}$ Therefore, a California taxpayer who contributed to an HSA is required to increase his or her California adjusted gross income by an amount equal to the sum of the taxpayer's HSA deduction on his or her federal return, the interest earned on the HSA, and the contributions made by the taxpayer's employer. This increase results in a larger state tax burden (or a smaller state tax refund) for the taxpayer.

\section{HDHP Enrollment and HSA Utilization}

\section{Data Challenges}

Although it would be beneficial to study the entire HSA population, which is the population that is eligible to establish and contribute to an HSA (i.e., enrolled in an HSA-eligible HDHP) and the population that has an HSA, few available data sources provide a comprehensive understanding of the entire HSA population. The lack of available data stems in part from the fact that HSAs and HSA-qualified HDHPs are two separate products. Although these two product populations overlap, they are not entirely identical, since not all HSA-qualified HDHP enrollees have established an HSA and not all HSA holders currently are enrolled in an HSA-qualified HDHP.

\footnotetext{
${ }^{50} 26$ U.S.C. $\$ 223(\mathrm{~d})(4)(\mathrm{A})$.

${ }^{51}$ IRS, Publication 969, pp. 6-7.

52 IRS, Internal Revenue Bulletin: 2004-2.

${ }^{53}$ If an individual is self-employed, the HSA deduction does not affect self-employment net earnings; as a consequence, HSA contributions are not exempt from Social Security and Medicare (Self-Employment Contribution Act or SECA) taxes. IRS, Internal Revenue Bulletin: 2004-33.

${ }^{54}$ IRS, Internal Revenue Bulletin: 2004-33, and IRS, Publication 969, p. 2.

${ }^{55}$ California Assembly Revenue and Taxation, AB 1140 (Obernolte) - As Amended January 3, 2018: Income Tax: Health Savings Accounts, committee print, prepared by California Assembly Revenue and Taxation Committee, Carlos Anguiano, January 5, 2018, pp. 2-4, at https://leginfo.legislature.ca.gov/faces/billAnalysisClient.xhtml?bill_id= $201720180 \mathrm{AB} 1140$.
} 
Furthermore, these products often can be administered by two separate institutions. Some individuals have their HSA established with their insurer, whereas others have their HSA administered by another type of institution, such as a bank. In the latter case, the insurer would not have any information regarding the individuals' HSAs (i.e., contributions, investments, or withdrawals). Inversely, the HSA holding institution likely would not be aware of the individuals' enrollment in or disenrollment from an HSA-qualified HDHP.

As a result, HSA research tends to focus on one of two populations, HSA-qualified HDHP enrollees or HSA holders. In light of these and other methodological limitations, existing HSA studies that rely on surveys of insurers, businesses, or HSA administrators or aggregate IRS tax data can often produce discrepancies in findings and make direct data comparisons difficult. ${ }^{56}$ In addition, there may be no data sources to answer key questions of interest, for example, how many individuals eligible to open an HSA or eligible to make an HSA contribution do so. Although exact point estimates for the entire HSA/HSA-qualified HDHP population are difficult to determine, current research, when referenced collectively, can highlight various trends. The next section highlights selected findings related to enrollment and contributions from a variety of commonly cited data sources.

\section{Data Findings}

Multiple different sources have demonstrated continued increases in HSA-qualified HDHP enrollment and HSAs since the mid-2000s. With respect to HSA-qualified HDHP enrollees, a report using survey data from insurers has shown a continued increase in enrollment in HSAeligible HDHPs sold by commercial insurers in the individual and the small- and large-group markets from 2005 through $2017 .{ }^{57}$ A report using survey data from employers with three or more workers has shown an increase in the percentage of covered employees in HSA-eligible HDHPs between 2006 and 2017. ${ }^{58}$ This survey of employers also revealed that larger employers are more likely than smaller employers to offer HSA-eligible HDHPs to employees. Specifically, in 2017, employers with 200 or more workers were more likely than employers with 3 to 199 workers to offer HSA-eligible HDHPs to employees. ${ }^{59}$

Similar to HDHP enrollment, multiple sources have indicated an increase in the number of HSA accounts. IRS tax return filer data have shown an increase in the number of tax filers reporting HSA contributions or withdrawals from 2004 to 2012, and HSA account administrator data have shown an increase in the number of accounts from 2011 to $2016 .{ }^{60}$

\footnotetext{
${ }^{56}$ As an example of methodological limitations, not all sources referenced in this report provide nationally representative estimates. Some referenced studies provide unadjusted results from surveys that do not use a random samples of the population being studied, and other studies use administrative data from a subsection of the population whose data is available. Such limitations restrict the ability to generalize these types of findings to the entire HSA and/or HSA-qualified HDHP populations.

${ }^{57}$ America's Health Insurance Plans, Health Savings Accounts and High Deductible Health Plans Grow as Valuable Financial Planning Tools, April 12, 2018, p. 3, https://www.ahip.org/2017-survey-of-health-savings-accounts/.

${ }^{58}$ Gary Claxton, Matthew Rae, and Michelle Long et al., Employer Health Benefits 2017 Annual Survey, Kaiser Family Foundation and Health Research and Educational Trust, September 19, 2017, p. 134, at http://files.kff.org/attachment/ Report-Employer-Health-Benefits-Annual-Survey-2017. Hereinafter Claxton, Rae, and Long et al., Employer Health Benefits.

${ }^{59}$ Claxton, Rae, and Long et al., Employer Health Benefits, p. 133.

${ }^{60}$ Lorens A. Helmchen, David W. Brown, and Ithai Z. Lurie, et al., "Health Savings Accounts: Growth Concentrated Among High-Income Households and Large Employers," Health Affairs Journal, vol. 34, no.9 (September 2015), p. 1594 https://www.healthaffairs.org/doi/abs/10.1377/hlthaff.2015.0480 (hereinafter Helmchen, Brown, and Lurie et al.,
} 
With respect to HSA contributions, the aforementioned sample of HSA account administrator data reveals that around half of account holders individually contributed to their HSAs in 2016 and around half received an employer contribution. ${ }^{61}$ With respect to employer contributions, two studies using HSA account administrator data from 2016 showed that HDHP-enrolled employees (who made contributions to HSAs) made an average employee contribution equal to roughly twice the average amount made by employers (that made contributions). ${ }^{62}$

The study of IRS tax filings from 2004 to 2012 indicated that the likelihood of contributing to an HSA increased with tax filer's age from 20 to about $45 .{ }^{63}$ The study also showed that, across all ages, the likelihood of tax filers contributing to an HSA and the likelihood of tax filers with an HSA maximizing their contributions (both individual and employer) increased across each income quintile. ${ }^{64}$ Finally, the analysis of HSA administrator data revealed that very few HSAs (fewer than $4 \%$ in 2016) have investments other than cash within the account, with older accounts being more likely than newer accounts to have invested funds. ${ }^{65}$

\section{Author Contact Information}

Ryan J. Rosso

Analyst in Health Care Financing

rrosso@crs.loc.gov,7-9995

\footnotetext{
"Health Savings Accounts"), and Paul Fronstin, Trends in Health Savings Account Balances, Contributions, Distributions, and Investments, 2011-2016: Statistics from the EBRI HSA Database, Employee Benefit Research Institute, July 11, 2017, p. 8, at https://www.ebri.org/pdf/briefspdf/EBRI_IB_434_HSAs.11July17.pdf (hereinafter Fronstin, Trends in Health Savings Account Balances, Contributions, Distributions, and Investments).

${ }^{61}$ Fronstin, Trends in Health Savings Account Balances, Contributions, Distributions, and Investments, p. 8, 10. The study does not provide information on the proportion of account holders who have both an individual and an employer contribution or only one type of contribution.

${ }^{62}$ Average employee HSA contributions (among those making contributions) were estimated to be $\$ 1,786$ and $\$ 1,987$ in two reports analyzing 2016 data. Employer contributions (among those making contributions) averaged $\$ 868$ and \$935, respectively. Devenir Research, 2016 Year-End HSA Market Statistics \& Trends Executive Summary, February 22, 2017, p. 5, at http://www.devenir.com/wp-content/uploads/2016-Year-End-Devenir-HSA-Market-Research-ReportExecutive-Summary-1.pdf, and Fronstin, Trends in Health Savings Account Balances, Contributions, Distributions, and Investments p. 10.

${ }^{63}$ Helmchen, Brown, and Lurie et al., "Health Savings Accounts," p. 1595.

${ }^{64}$ Helmchen, Brown, and Lurie et al., "Health Savings Accounts," p. 1596.

${ }^{65}$ Fronstin, Trends in Health Savings Account Balances, Contributions, Distributions, and Investments, p. 14.
} 